\title{
Simple bone cyst of the hyoid: A radiological diagnosis and follow-up
}

\section{Torbiel samotna kości gnykowej - rozpoznanie radiologiczne i badanie kontrolne}

\author{
Nagihan Koç, $1, A, B, D, F$, Şafak Parlak²,B,,$E$ \\ ${ }^{1}$ Department of Dentomaxillofacial Radiology, Hacettepe University, Ankara, Turkey \\ ${ }^{2}$ Department of Radiology, Hacettepe University, Ankara, Turkey \\ A - research concept and design; B - collection and/or assembly of data; $C$ - data analysis and interpretation; \\ $D$ - writing the article; $E$ - critical revision of the article; $F$ - final approval of the article
}

\section{Address for correspondence \\ Nagihan Koç}

E-mail: nagihan.koc@hacettepe.edu.tr

Funding sources

None declared

Conflict of interest

None declared

Received on March 2, 2020

Reviewed on March 28, 2020

Accepted on April 5, 2020

Published online on September 30, 2020

\begin{abstract}
Simple bone cyst (SBC), also known as unicameral bone cyst, is a benign, fluid-filled cystic lesion that mainly appears in the long bones of young patients. Simple bone cysts are considered dysplastic or reactive lesions of bone. The most common locations for SBCs are the proximal humerus and femur. Lesions may occasionally be found in the jawbones. Simple bone cysts often have no clinical impact and are usually detected during routine radiographic examinations unless a gross pathologic fracture occurs. When symptoms develop, they may include mild pain, local tenderness and swelling. Computed tomography (CT) scans demonstrate a central, well-defined, mildly expansile or non-expansile, thin-walled lytic lesion, with little or no marginal sclerosis. Magnetic resonance imaging (MRI) usually confirms the cystic nature of the lesion by showing its fluid content. Cystic masses in the hyoid bone are very rare. Here we report an asymptomatic SBC in the hyoid bone, incidentally discovered in a cone-beam computed tomography (CBCT) examination, which appears to be the $2^{\text {nd }}$ reported case.
\end{abstract}

Key words: simple bone cyst, aneurysmal bone cyst, hyoid bone, thyroglossal cyst

Słowa kluczowe: samotna torbiel kostna, torbiel tęniakowa kości, kość gnykowa, torbiel przewodu tarczowo-językowego

Cite as

Koç N, Parlak Ş. Simple bone cyst of the hyoid: A radiological diagnosis and follow-up. Dent Med Probl. 2020;57(3):333-337. doi:10.17219/dmp/120079

DOI

$10.17219 / \mathrm{dmp} / 120079$

Copyright

(C) 2020 by Wroclaw Medical University

This is an article distributed under the terms of the

Creative Commons Attribution 3.0 Unported License (CC BY 3.0)

(https://creativecommons.org/licenses/by/3.0/) 


\section{Introduction}

Simple bone cyst (SBC) is a benign, fluid-filled cystic lesion, which constitutes approx. $3 \%$ of all bone tumors, and mainly appears in the long bones of predominantly male children and adolescents. ${ }^{1}$ Simple bone cysts lack an epithelial lining; therefore, they do not represent true cysts. Several names have been used as synonyms for $\mathrm{SBC}$, including idiopathic bone cavity, unicameral bone cyst (UBC), traumatic bone cyst, hemorrhagic bone cyst, solitary bone cyst, and extravasation cyst. ${ }^{2}$ The etiology and pathogenesis of SBC are not completely understood, as can be seen from the wide variety of synonyms. The proposed causative mechanisms include trauma, obstruction in the venous flow in bone marrow sinusoids, and a growth defect in the epiphyseal plate. ${ }^{1}$

Simple bone cysts have been largely found in the metaphyseal areas of long bones, with the majority in 2 locations - the proximal humerus and femur. ${ }^{1}$ The occurrence of SBC elsewhere is uncommon. Lesions may occasionally be found in the jawbones. ${ }^{3}$

On imaging, SBCs usually present as well-defined, unilocular radiolucency, but they may also have multilocular or separated appearance. ${ }^{2,4}$ These lesions are usually asymptomatic and found incidentally. Pain and swelling may be the reasons for presentation, and a pathological fracture may also occur. ${ }^{5}$

Histologically, a cyst cavity is lined with a thin fibrous membrane, which may contain reactive bone, hemorrhage, inflammatory granulation tissue, and bone fragments. $^{6}$

Treatment methods for SBCs include observation, steroid injection, autologous bone marrow injection, decompression, and open curettage with a bone graft. $^{7}$

The cystic lesions of the hyoid bone are rare and have been seldom reported in the literature. Here we report an incidentally discovered SBC in the hyoid bone, which might be interesting, as it is extremely rare and has been reported only once before. ${ }^{8}$

\section{Case report}

An 18-year-old male patient was referred to the Department of Dentomaxillofacial Radiology at Hacettepe University in Ankara, Turkey, for cone-beam computed tomography $(\mathrm{CBCT})$ in order to evaluate the maxillofacial region prior to orthodontic treatment. Scans were obtained with the i-CAT ${ }^{\mathrm{TM}}$ Next Generation device (Imaging Sciences International, Hatfield, USA), using a field-ofview of $160 \times 100 \mathrm{~mm}$ (tube voltage: $120 \mathrm{kVp}$; tube current: $5 \mathrm{~mA}$; exposure time: $7 \mathrm{~s}$; voxel: $0.2 \mathrm{~mm}$ ). During the evaluation of CBCT images, a solitary, circumscribed, osteolytic, well-defined lesion involving the body of the mid-hyoid bone was found (Fig. 1). The lesion had dimensions of approx. $5.6 \mathrm{~mm} \times 4.8 \mathrm{~mm}$ and showed corticated margins. Slight cortical expansion, erosion and thinning were noted. The patient had no history of pain, dysphagia, previous neck surgery or trauma. No associated cervical lymphadenopathy was present and the rest of the physical examination was unremarkable.

The patient returned to the Department 3 years later with no symptoms, and then he was referred for magnetic resonance imaging (MRI). An MRI examination was performed with a 3.0T scanner (SIGNA ${ }^{\mathrm{TM}}$ Architect; GE Healthcare, Milwaukee, USA) by using a standard neck coil. The standard neck protocol included fat-saturated (fat-sat) T2-weighted imaging, T1-weighted imaging, pre- and post-contrast with and without fat-sat T1-weighted imaging, and diffusionweighted imaging (DWI) $(b=600)$. The intravenous administration of a contrast agent with gadolinium was performed at a dose of $0.1 \mathrm{mmol} / \mathrm{kg}$. Axial three-dimensional (3D) constructive interference in steady-state (CISS) imaging was added to the protocol due to the small size of the lesion. Magnetic resonance imaging revealed a T1 hypointense and $\mathrm{T} 2$ hyperintense cystic lesion in the hyoid bone without any solid or soft tissue component (Fig. 2,3). The lesion showed no contrast enhancement or diffusion restriction. There were no internal septation or fluid-fluid levels. The radiographic examinations were suggestive of SBC in the diagnosis. Then, clinical and radiographic follow-up was planned.

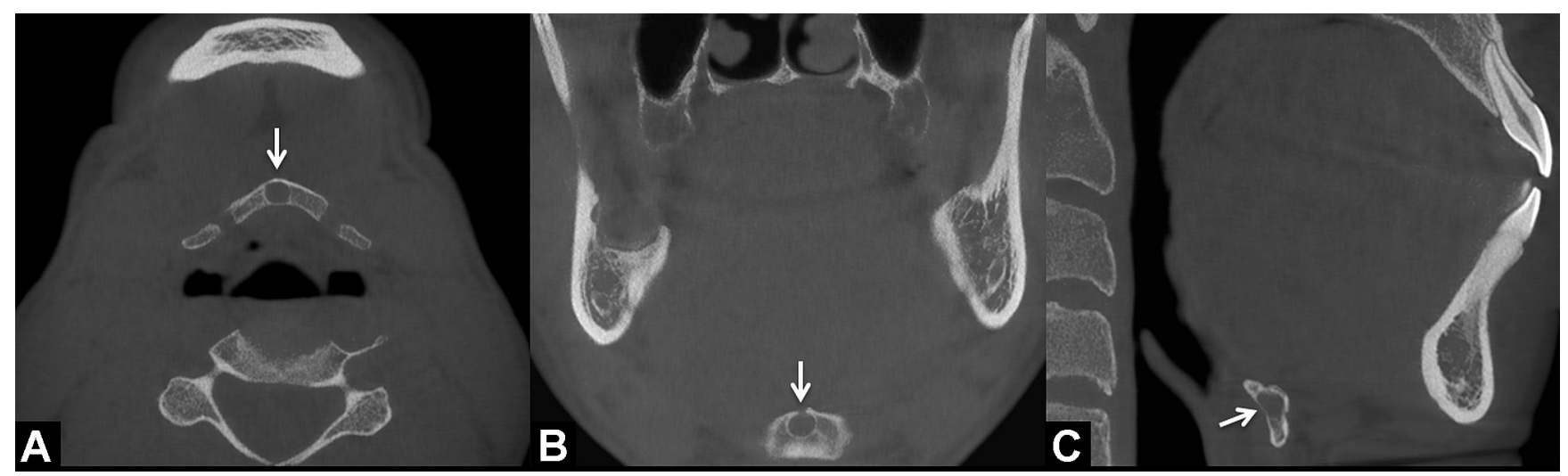

Fig. 1. Cone-beam computed tomography (CBCT) images showing a well-defined osteolytic lesion (arrow) involving the body of the mid-hyoid bone A - axial view; $B$ - coronal view; C - sagittal view. 


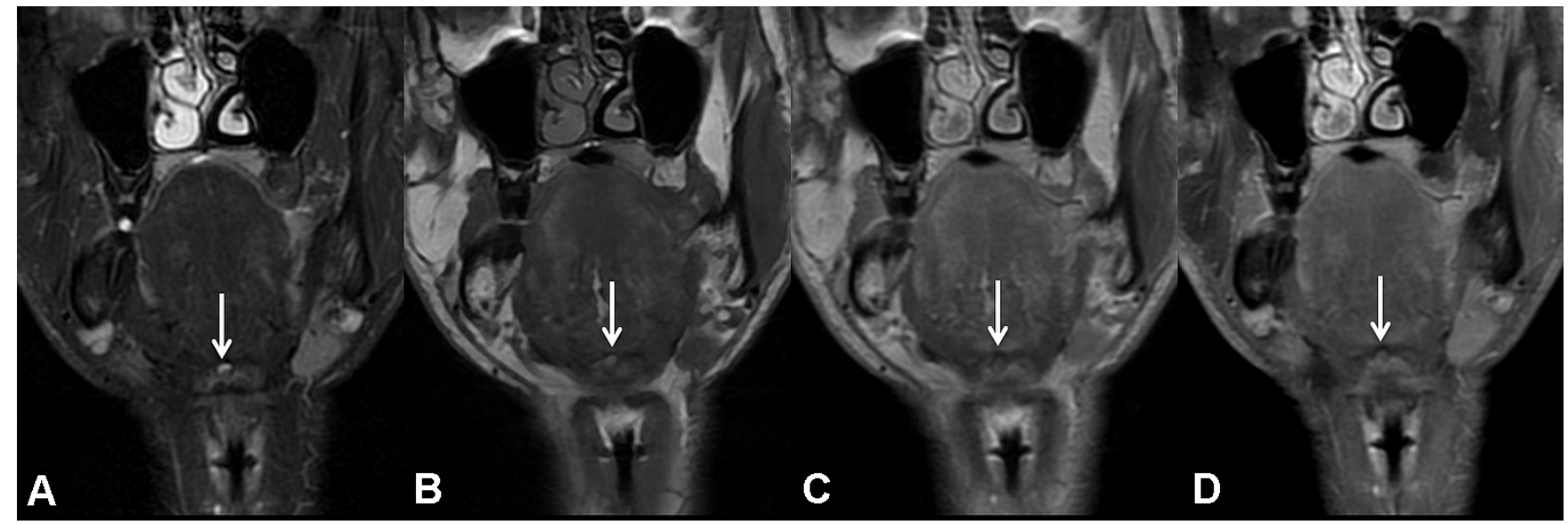

Fig. 2. Coronal magnetic resonance imaging (MRI) sections of the head show that the lesion (arrow) in the hyoid bone appears hyperintense on fat-saturated (fat-sat) T2-weighted images (A) and hypointense on T1-weighted images (B); after contrast administration, the lesion demonstrates no enhancement on T1-weighted images (C) and fat-sat T1-weighted images (D)

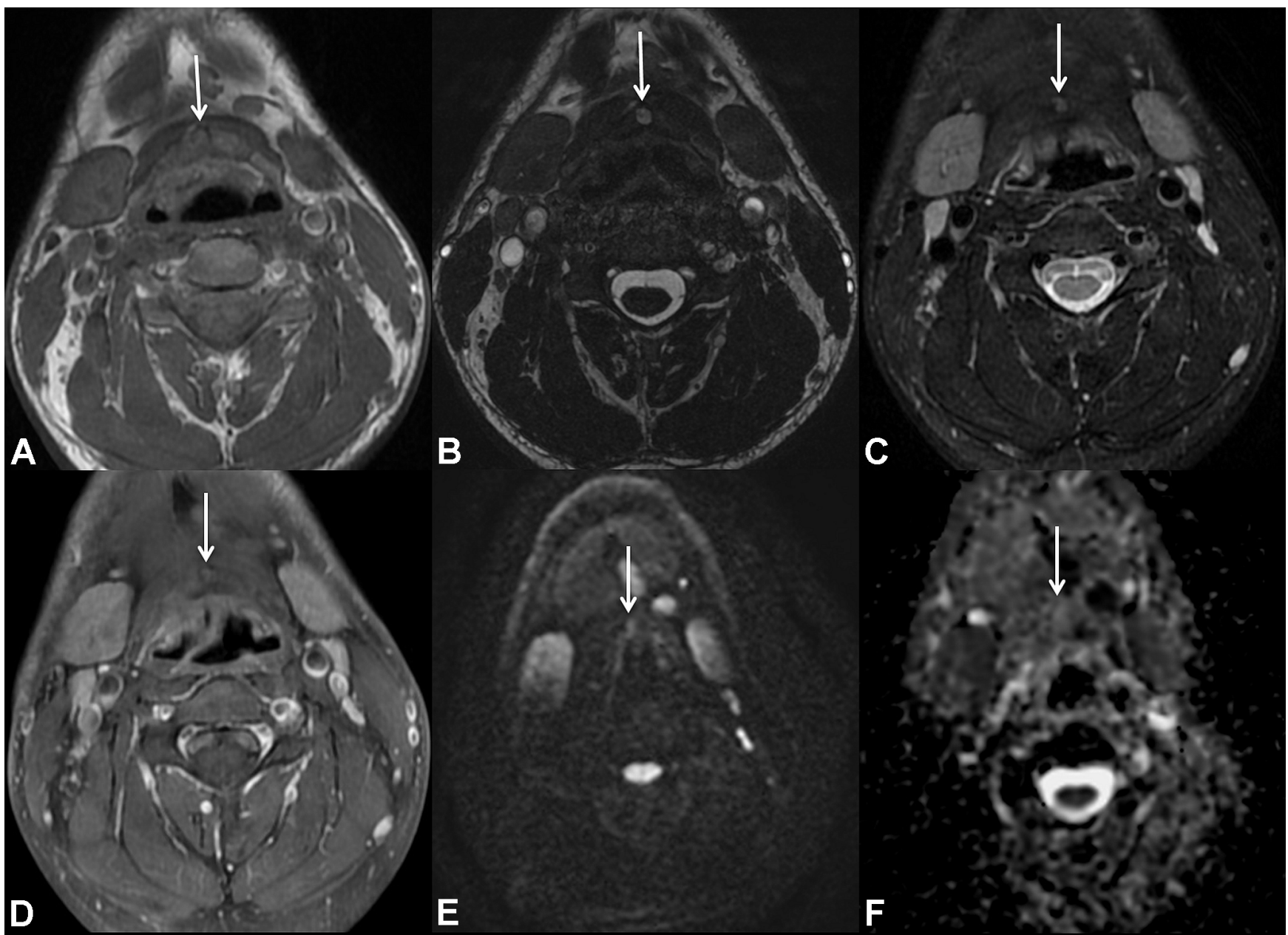

Fig. 3. Axial magnetic resonance imaging (MRI) sections of the head show that the hyoid lesion (arrow) appears hypointense on T1-weighted images (A) and hyperintense on T2-weighted three-dimensional (3D) constructive interference in steady-state (CISS) imaging (B) and fat-saturated (fat-sat) (C) images; after gadolinium administration, the lesion demonstrates no contrast enhancement on fat-sat T1-weighted images (D); the lesion shows no restricted diffusion on diffusion-weighted imaging (DWI) (E) and on the apparent diffusion coefficient (ADC) map (F)

\section{Discussion}

Cystic masses in the hyoid bone are quite rare and there have been 6 cases reported in the literature to date, including 4 thyroglossal duct cysts (TDCs), ${ }^{9-12} 1$ aneurysmal bone cyst $(\mathrm{ABC}),{ }^{13}$ and $1 \mathrm{UBC}$ or SBC. ${ }^{8}$ Cases of TDC penetrating the hyoid bone have also been reported. ${ }^{14,15}$

Thyroglossal duct cyst is typically located in the midline and is the most common congenital neck mass that occurs due to the incomplete obliteration of the thyroglossal duct. 
Histologically, cyst walls contain an epithelial lining. Thyroglossal duct cysts can occur anywhere along the course of the thyroglossal duct, with the majority being associated with the hyoid region. ${ }^{16}$ The most frequent location for TDCs is in the infrahyoid muscles, below the hyoid bone. The diagnosis of TDC can be made clinically, as it typically presents as a mobile midline structure, which increases in size over time and moves cranially with swallowing and the protrusion of the tongue because of its close relationship with the hyoid bone and the foramen cecum. On computed tomography $(\mathrm{CT})$ imaging, TDCs appear as well-circumscribed masses with mucoid attenuation. On MRI, TDCs show low signal intensity with T1-weighted imaging, high signal intensity with T2-weighted imaging and do not demonstrate restricted diffusion. ${ }^{17}$ In the presence of infection, peripheral rim enhancement and wall thickening can be observed in TDCs on both CT and magnetic resonance (MR) images after the intravenous injection of contrast material. ${ }^{18}$

Aneurysmal bone cysts are benign, expansile, tumorlike lesions consisting of blood-filled spaces contoured by fibrous septa that especially involve long bones, the spine and the pelvis in young patients. The lesion is classified as primary $A B C$ if no underlying lesion is present, and as secondary if the lesion occurs in association with other tumors. ${ }^{3}$ The exact etiology is unknown, but the proposed mechanism in secondary $A B C$ includes intraosseous or subperiosteal hemorrhage, and osteolysis due to trauma. Although $\mathrm{ABCs}$ are relatively rare in the head-neck region and the mandible is the most common site of occurrence, a case of $\mathrm{ABC}$ has been described in the hyoid bone. The plain radiographic features of $A B C$ include soap-bubble, honeycomb or multilocular cystic appearance, which may cause the expansion or destruction of cortical bone. ${ }^{19}$ The found multiple internal septa with fluid-fluid levels caused by the separation of the hemorrhagic components, which is better observed on MRI, is pathognomonic in many cases. On an MRI scan, the lesion shows low to intermediate signal intensity with T1-weighted imaging and high signal intensity with T2-weighted imaging. ${ }^{3}$

Simple bone cysts are solitary cavities that are considered dysplastic or reactive lesions of bone. ${ }^{3}$ The exact etiopathology remains unclear. Trauma has been postulated in the etiology, as it may cause an intramedullary hematoma, which eventually invokes bone resorption. ${ }^{20}$ However, the incidence of a traumatic injury in patients with SBCs is not higher as compared to that of the general population. ${ }^{21}$ Moreover, it appears that in many cases of SBC, there has been no history of a traumatic injury. ${ }^{4}$

Since the lesions predominantly occur in young patients, during the period of active bone growth, the theory of localized disturbance in bone metabolism or bone growth has also been considered in the pathogenesis of SBCs. ${ }^{22,23}$

Simple bone cysts often have no clinical impact and the lesions are usually detected during routine radiographic examinations unless a gross pathologic fracture occurs.
When symptoms develop, they may include mild pain, local tenderness and swelling. ${ }^{5}$

The typical radiographic appearance of the lesion is unilocular radiolucency with well-circumscribed borders. ${ }^{2}$ A CT scan demonstrates a central, well-defined, mildly expansile or nonexpansile, thin-walled lytic lesion, with little or no marginal sclerosis. ${ }^{1}$ There can be partial septa or a pseudo-septum in the cystic cavity. ${ }^{3}$ Magnetic resonance imaging usually confirms the cystic nature of the lesion by showing its fluid content. Fluid-fluid levels are rarely seen. However, fractured SBCs may contain blood products and fluid-fluid levels. On MRI, the lesion shows low signal intensity on T1-weighted images, and high signal intensity on T2-weighted or Short Tau Inversion Recovery (STIR) images. ${ }^{5}$

Simple bone cysts are considered to be self-limiting benign lesions that heal spontaneously after skeletal maturity. ${ }^{24}$ Moreover, several studies have described the spontaneous resolution of the lesions over time. ${ }^{24-28}$ Thus, it has been suggested that non-interventional treatment (observation) could be chosen as an alternative to surgical approaches in cases when a radiologic diagnosis is possible, particularly in young patients with asymptomatic cysts. ${ }^{24,27,29}$

In the present case, the clinical and radiographic features of the solitary lesion in the hyoid bone were strongly indicative of SBC. No surgical pathologic examination was performed, as the patient was asymptomatic for at least 3 years, and there was no sign of fracture of the cyst or an increase in the size of the lesion over time. For these reasons, the periodic observation of the patient was decided.

In conclusion, although cystic lesions rarely occur in the hyoid bone, SBC should be considered in the diagnosis of a well-circumscribed, radiolucent lesion in the hyoid bone of a young patient.

\section{ORCID iDs}

Nagihan Koç (D) https://orcid.org/0000-0002-3339-7783 Şafak Parlak (D) https://orcid.org/0000-0002-6028-4653

\section{References}

1. Kalil RK, Araujo ES. Simple bone cyst. In: Fletcher CDM, Unni KK, Mertens F, eds. World Health Organization Classification of Tumours. Pathology and Genetics of Tumours of Soft Tissue and Bone. Lyon, France: IARC Press; 2002:340.

2. Neville BW, Damm DD, Allen CM, Chi AC. Bone pathology. In: Neville BW, Damm DD, Allen CM, Chi AC, eds. Oral and Maxillofacial Pathology. $4^{\text {th }}$ ed. St. Louis, MO: Elsevier; 2015:589-591.

3. Mascard E, Gomez-Brouchet A, Lambot K. Bone cysts: Unicameral and aneurysmal bone cyst. Orthop Traumatol Surg Res. 2015;101(Suppl 1):S119-S127.

4. Chrcanovic BR, Gomez RS. Idiopathic bone cavity of the jaws: An updated analysis of the cases reported in the literature. Int J Oral Maxillofac Surg. 2019;48(7):886-894.

5. Noordin S, Allana S, Umer M, Jamil M, Hilal K, Uddin N. Unicameral bone cysts: Current concepts. Ann Med Surg (Lond). 2018;34:43-49.

6. An SY, Lee JS, Benavides E, et al. Multiple simple bone cysts of the jaws: Review of the literature and report of three cases. Oral Surg Oral Med Oral Pathol Oral Radiol. 2014;117(6):e458-e469.

7. Lee SY, Chung CY, Lee KM, et al. Determining the best treatment for simple bone cyst: A decision analysis. Clin Orthop Surg. 2014;6(1):62-71. 
8. Wang AS, McCoul ED, Anand VK. Unicameral bone cyst of the hyoid. Otolaryngol Head Neck Surg. 2012;146(1):171-172.

9. Tas A, Karasalihoglu AR, Yagiz R, Doğanay L, Guven S. Thyroglossal duct cyst in hyoid bone: Unusual location. J Laryngol Otol. 2003;117(8):656-657.

10. Bourjat P, Cartier J, Woerther JP. Thyroglossal duct cyst in hyoid bone: CT confirmation. J Comput Assist Tomogr. 1988;12(5):871-873.

11. Zhou W, Bai JB, Yu LP, Zhang WD. Cyst in the hyoid bone: A case report and review of the literature. Int J Clin Exp Med. 2019;12(8):10950-10954.

12. Podoshin L, Fradis M, Goldstein J, Misselevitch I, Boss JH. Intrahyoid thyroglossal cyst. J Laryngol Otol. 1989;103(5):539-542.

13. Shadaba A, Zaidi S. Aneurysmal bone cyst of the hyoid. J Laryngol Otol. 1992;106(1):71-72.

14. Horisawa M, Sasaki J, Niinomi N, Yamamoto T, Ito T. Thyroglossal duct remnant penetrating the hyoid bone - a case report. J Pediatr Surg. 1998;33(5):725-726.

15. Seow-En I, Loh AHP, Lian DWQ, Nah SA. Thyroglossal duct cyst carcinoma: Diagnostic and management considerations in a 15-year-old with a large submental mass. BMJ Case Rep. 2015;2015:bcr2015210923.

16. Tracy TF Jr., Muratore CS. Management of common head and neck masses. Semin Pediatr Surg. 2007;16(1):3-13.

17. Meuwly JY, Lepori D, Theumann N, et al. Multimodality imaging evaluation of the pediatric neck: Techniques and spectrum of findings. Radiographics. 2005;25(4):931-948.

18. Zander DA, Smoker WRK. Imaging of ectopic thyroid tissue and thyroglossal duct cysts. Radiographics. 2014;34(1):37-50.

19. Asaumi J, Konouchi $\mathrm{H}$, Hisatomi M, et al. MR features of aneurys mal bone cyst of the mandible and characteristics distinguishing it from other lesions. Eur J Radiol. 2003;45(2):108-112.

20. Olech E, Sicher H, Weinmann JP. Traumatic mandibular bone cysts. Oral Surg Oral Med Oral Pathol. 1951;4(9):1160-1172.

21. Kaugars GE, Cale AE. Traumatic bone cyst. Oral Surg Oral Med Oral Pathol. 1987;63(3):318-324.

22. Ogden JA, Griswold DM. Solitary cyst of the talus. J Bone Joint Surg Am. 1972;54(6):1309-1310.

23. Jaffe HL, Lichtenstein L. Solitary unicameral bone cyst with emphasis on the roentgen picture, the pathologic appearance and the pathogenesis. Arch Surg. 1942;44(6):1004-1025.

24. Wilkins RM. Unicameral bone cysts. J Am Acad Orthop Surg. 2000;8(4):217-224.

25. Sapp JP, Stark ML. Self-healing traumatic bone cysts. Oral Surg Oral Med Oral Pathol. 1990;69(5):597-602.

26. Damante JH, Da S Guerra EN, Ferreira O Jr. Spontaneous resolution of simple bone cysts. Dentomaxillofac Radiol. 2002;31(3):182-186.

27. Neer CS $2^{\text {nd }}$, Francis KC, Marcove RC, Terz J, Carbonara PN. Treatment of unicameral bone cyst. A follow-up study of one hundred seventy-five cases. J Bone Joint Surg Am. 1966;48(4):731-745.

28. Battisti MdPL, Soares MQS, Rubira CMF, Rubira de Bullen IRF, Lauris JRP, Damante JH. Assessment of spontaneous resolution of idiopathic bone cavity. J Appl Oral Sci. 2018;26:e20170288.

29. Green NM, Pagkalos J, Jeys LM, Stevenson JD, Gregory JJ. Humeral simple bone cysts: Observational versus interventional management. J Pediatr Orthop. 2019;39(6):e472-e477. 